\title{
Francesca Piselli, Féraud versus Racine. Riflessioni sulla lingua
}

\section{Graziano Benelli}

\section{(2) OpenEdition}

\section{Journals}

\section{Edizione digitale}

URL: http://journals.openedition.org/studifrancesi/4374

DOI: 10.4000/studifrancesi.4374

ISSN: 2421-5856

\section{Editore}

Rosenberg \& Sellier

\section{Edizione cartacea}

Data di pubblicazione: 1 settembre 2016

Paginazione: 330-331

ISSN: 0039-2944

\section{Notizia bibliografica digitale}

Graziano Benelli, «Francesca Piselli, Féraud versus Racine. Riflessioni sulla lingua », Studi Francesi

[Online], 179 (LX | II) | 2016, online dal 01 septembre 2016, consultato il 18 septembre 2020. URL http://journals.openedition.org/studifrancesi/4374 ; DOI : https://doi.org/10.4000/studifrancesi.4374

Questo documento è stato generato automaticamente il 18 settembre 2020.

\section{(c) $(7)$}

Studi Francesi è distribuita con Licenza Creative Commons Attribuzione - Non commerciale - Non opere derivate 4.0 Internazionale. 


\title{
Francesca Piselli, Féraud versus Racine. Riflessioni sulla lingua
}

\author{
Graziano Benelli
}

\section{NOTIZIA}

FRANCESCA PISELLI, Féraud versus Racine. Riflessioni sulla lingua, Roma, Aracne, «Recherches sur Toiles» 8, 2014, 124 pp.

1 Il volume prende in esame le remarques presenti nell'opera più nota dell'abate gesuita Jean-François Féraud (1725-1807), ovvero il Dictionaire critique de la langue française, apparso a Marsiglia tra il 1787 e il 1788, con particolare riferimento alla lingua di Jean Racine. Caso ibrido e appassionante di descrizione normativa, stilistica e retorica, costruito tramite l'insostituibile apporto di scrittori e grammairiens-remarquistes, il Dictionaire critique de la langue française si contraddistingue per un'osservazione accorta degli usi, oltre che per una minuziosa riflessione sui criteri ispiratori della norma. Esso rappresenta una fonte d'informazione importante per indagare sui fenomeni soggetti a cambiamento o a stabilizzazione nel francese della seconda metà del Settecento. Analizzando le numerose citazioni presenti nel celebre dizionario critico riguardanti Racine (che Féraud definisce «le plus correct de nos poètes», p. 18), e soprattutto esaminando le annotazioni dell'abate sulla lingua e sullo stile di Racine, Francesca Piselli ha modo di condurre un'analisi quanto mai mirata e sempre condotta con grande rigore filologico.

2 Nel primo dei tre capitoli che compongono il lavoro («Tra lingua e stile»), l'autrice ricorda che per Féraud la lingua di Racine, il più classico tra i classici, resta il modello cui ispirarsi per contrastare certo «mauvais goût» (p. 21), che vedeva diffondersi tra i suoi contemporanei. Questo suo convincimento va di pari passo con la tensione purista che anima il Dictionaire critique, tensione che, come conferma la rilevante tradizione in materia di remarques e observations di opere di autori classici, percorre tutto il XVIII secolo. 
3 La costante attenzione verso l'uso rende più indulgente l'abate gesuita, che imputa a taluni cambiamenti d'uso e di gusto rispetto al Seicento le imperfezioni stilistiche delle tragedie giovanili di Racine. La scelta dei vocaboli nello stile poetico, stile nobile per eccellenza, risulta essenziale, ma non sempre Racine ha compiuto, secondo Féraud, le scelte giuste. Tuttavia egli riconosce al tragediografo l'art de l'annoblissement, ossia l'arte di nobilitare i termini bassi e/o popolari e di forgiare espressioni semplici e al contempo elevate, come confermano i numerosi esempi citati nel Dictionaire critique.

Il secondo capitolo («Il senso delle parole») è incentrato sulle osservazioni di Féraud riguardo al lessico raciniano e, in particolare, su alcuni meccanismi per così dire obiettivi, talora operati direttamente da Racine, sui quali il lessicografo marsigliese esprime il proprio parere, a dire il vero non sempre benevolo. Agli elogi nei confronti di Racine per la sua capacità di sfruttare le accezioni secondarie e meno comuni di un termine, instillando nel verso inedite sfumature di significato, si accompagnano però le note di biasimo per alcune sue imprecisioni circa l'utilizzo di un verbo al posto di un altro. Va anche detto che, partendo da un'analisi sincronica, Féraud arriva a prendere in considerazione anche la dimensione lessico-semantica più propriamente diacronica .

Il terzo capitolo è incentrato sulla «Sintassi» che, nel xviII secolo, tendeva alla fixité, ma che di fatto necessitava, a detta di Féraud, di una stabilizzazione in molti ambiti. Francesca Piselli, passando in rassegna tutte le remarques dell'abate marsigliese riguardo al gruppo nominale (accordo, articolo partitivo, régime degli aggettivi), ai pronomi, al gruppo verbale (costruzione dei verbi, classi verbali, verbes neutres e accordo dei participi), alle parti invariabili del discorso e all'ordine delle parole nella frase, sottolinea come Féraud guardi alla lingua di Racine e alla sua sintassi cercando di attualizzare un ideale di lingua classica che, di fatto, è ormai postclassica, visto che compila il suo dizionario oltre un secolo dopo la composizione dei capolavori raciniani.

6 Nelle annotazioni del lessicografo si colgono tutti i flottements e i mutamenti in corso nel Settecento ed è per questo che l'autore classico per eccellenza appare non sufficientemente classico. Resta comunque qualche ambiguità di fondo, come il fatto di censurare un buon numero di passi raciniani invocando la fedeltà alla norma, salvo poi ammettere un altrettanto discreto numero di scarti in nome del gusto e della nobiltà della lingua poetica.

7 Il volume, corredato di un'ampia bibliografia e dell'indice dei nomi e delle opere, si segnala per la coerenza e per la scientificità dell'impostazione, e apporta sicuramente nuovo materiale di riflessione alle ricerche sul francese del Settecento. 